\title{
Adult congenital heart disease physical activity recommendation form: a feasibility study
}

Teresa Lyle ${ }^{1}$ and Melissa Hartman ${ }^{2 *}$

\begin{abstract}
Background: Adults with Congenital Heart Disease (ACHD) follow the same physical inactivity patterns as the general population. It is well known that physical inactivity is a risk factor for cardiovascular disease, and even more significant in the ACHD population. Health fears and misconceptions are common barriers to physical activity despite evidence supporting safety and efficacy of many activities for ACHD patients.
\end{abstract}

Methods: Feasibility Study with a convenience sample of 65 participants. The participants represented more moderate and complex diagnosis categorization. Participants completed the Stanford Brief Activity Survey (SBAS) and the Stanford Patient Education Research Questionnaire for Chronic Disease during enrollment. Participants received a Physical Activity Recommendation Form (PARF) with written instructions for utilization of the form at their next routine ACHD Provider clinic visit. Following use of the PARF, study participants completed a second SBAS and a PARF Utilization Satisfaction Survey, both returned in a pre-addressed envelope via regular mail to the investigators.

Results: Baseline data central tendency analysis determined 33\% were not active, $43 \%$ were insufficiently active, and $24 \%$ were sufficiently active to obtain activity related health benefits. The majority of the lifestyle scores for all four indicators were in the (8-10 range) indicative of participant confidence in managing symptoms impacting activity of daily living. Much less confidence (3-5 range) in managing symptoms of fatigue, pain, and emotional distress. 80\% of the PARF Utilization Surveys reported that use gave them more confidence in increasing activity level and less anxiety about exercise. $90 \%$ recommended PARF use for other ACHD patients. 50\% reported an increase in physical activity following use of the PARF and study participation.

Conclusion: The ACHD Physical Activity Advocacy Study raised awareness and increased confidence in discussing physical activity with specialty ACHD healthcare providers for the ACHA study participants. Perceived benefit from the utilization of the PARF was paramount, but several interesting results related to activity and lifestyle were also demonstrated: only $24 \%$ were identified as sufficiently active and less than half expressed confidence in managing anxiety. Therefore, more research in this population is needed to better define the relationship between anxiety and activity levels to determine appropriate interventions for patient empowerment.

Trial registration: Trial registration, retrospective/pending, exempt low risk study per IRB approval and not indicated.

Keywords: Congenital heart defects, Physical activity, Physical activity recommendations, Adult congenital heart association, Anxiety, Empowerment

\footnotetext{
* Correspondence: m.conway-hartman@unf.edu

${ }^{2}$ Department of Clinical and Applied Movement Sciences, University of North

Florida, Jacksonville, Florida, USA

Full list of author information is available at the end of the article
}

(c) The Author(s). 2018 Open Access This article is distributed under the terms of the Creative Commons Attribution 4.0 International License (http://creativecommons.org/licenses/by/4.0/), which permits unrestricted use, distribution, and reproduction in any medium, provided you give appropriate credit to the original author(s) and the source, provide a link to the Creative Commons license, and indicate if changes were made. The Creative Commons Public Domain Dedication waiver (http://creativecommons.org/publicdomain/zero/1.0/) applies to the data made available in this article, unless otherwise stated. 


\section{Background}

Regular physical activity participation is associated with a reduction in cardiovascular disease risk and improvements in physical and psychological health [2]. Adults with Congenital Heart Disease (ACHD) is the fastest growing population of survivors of childhood chronic illness with emerging morbidity that may be compounded by sedentary lifestyle $[3,4]$. National recommendations from the American College of Sports Medicine [5] and the United States Department of Health and Human Services (DHHS): Moderate physical activity at least $30 \mathrm{~min} /$ day or $150 \mathrm{~min} /$ week with a minimum recommendation of 10-30 min daily summarized by the DHHS statement "Any activity is better than no activity." $[5,6]$ Special chronic disease populations have even greater risks associated with sedentary lifestyle [2, 5].

The ACHD population follows the same physical inactivity patterns as the general population [2]. It is well known that physical inactivity is a risk factor for cardiovascular disease, including coronary artery disease with increased incidence of myocardial infarction (MI) [8]. An increased prevalence of $\mathrm{MI}$ in $\mathrm{ACHD}$ patients, greater than the general population, has been documented [7]. Health fears and misconceptions are common barriers to physical activity in ACHD, despite evidence supporting safety and efficacy of many activities [1]. The anxiety associated with these barriers prevent higher level daily activity above normal activities of daily living and light walking, especially in the ACHD population [8]. The desire for empowering patients to seek recommendations to boost confidence for increasing physical activity prompted a research study.

The purpose of the ACHD Physical Activity Advocacy Study was to empower patients to discuss individual physical activity recommendations with their ACHD specialist via the implementation of a Physical Activity Recommendation Form (PARF) [9] within 6 months of study enrollment. ACHA members often share fears regarding increase in regular physical activity and exercise during focused discussion groups. Some did not want to have an exercise stress test, and others expressed a lack of confidence to discuss or ask questions during routine ACHD visits [10]. The study aimed to determine if utilization of the PARF was beneficial to ACHD patients and if motivation for increased physical activity and improved health achieved. Feasibility of posting access to the PARF for self-care and patient advocacy via central forum such as the Adult Congenital Heart Association website was also considered. The study focus was not on the implementation of the actual written daily activity recommendations, but the experience and perceived benefit of utilization of the PARF.

\section{Methodology}

The ACHD Physical Activity Advocacy Study was a collaborative project designed by two collegiate institution professors and the Adult Congenital Heart Association (ACHA) [10], a very active patient advocacy/support organization. Institutional Review Board approval was obtained and informed consent signed by all participants. Anonymity was maintained with de-identified study numbers on all pre/ post questionnaires. The study investigators enrolled a convenience sample of 68 participants in attendance at the ACHA conference. Conference attendees visited the research room if they had interest in study participation. All participants were welcome and several bilingual patients participated and no interpreter services were needed. Three were disqualified due to incomplete SPERQ forms. In the end, data from 65 participants, 70\% female was analyzed. Population demographics is displayed in Table 1. Participants were grouped per ACHD guidelines as simple, moderate, and complex diagnosis categorization as noted in Table 2. The descriptive study design was based on the following research questions.

\section{Research questions posed}

1. What is the self-reported physical activity level (ages 18-65) prior to a U.S. implementation of a Physical Activity Recommendation Form (PARF) [8]?

Table 1 Population Study Demographics. This table includes the age range, gender, marital status, educational status and ethnicity of study participants

\begin{tabular}{|c|c|c|c|c|c|}
\hline \multirow[t]{2}{*}{ Age } & $18-25$ & $26-34$ & $35-41$ & $42-49$ & $50>$ \\
\hline & 5 & 15 & 13 & 12 & 21 \\
\hline \multirow[t]{2}{*}{ Gender } & Male & Female & & & \\
\hline & 19 & 46 & & & \\
\hline \multirow[t]{2}{*}{ Ethnicity } & White & Black & Hispanic & Asian/Pacific & \\
\hline & 60 & 1 & 3 & 1 & \\
\hline \multirow[t]{2}{*}{ Marital Status } & Married & Single/Separated & Divorced & & \\
\hline & 40 & $21 / 1$ & 3 & & \\
\hline \multirow[t]{2}{*}{ Education level } & High School & College & Graduate & & \\
\hline & 2 & 36 & 27 & & \\
\hline
\end{tabular}


Table 2 Summary of congenital heart disease diagnoses represented in the study sample. This table includes all the congenital heart defects represented in the study

\begin{tabular}{lll}
\hline Simple & Moderate & Complex \\
$n=2$ & $n=31$ & $\mathrm{~N}=29$ \\
\hline Atrial septal defect & Tetralogy of Fallot & Single Ventricle \\
& Aortic Stenosis & Tricuspid Atresia \\
& Transposition of the & Double Outlet Right \\
& Great Arteries & Ventricle \\
& Pulmonary Stenosis & Pulmonary Atresia \\
\hline
\end{tabular}

2. Does the lack of a standardized PARF present a perceived barrier for ACHD specialists in providing activity advice?

3. Does fear/anxiety about a congenital heart condition present a barrier to pursuit of physical activity?

4. Does implementation of a PARF as a self-care advocacy tool empower ACHD patients to discuss and obtain written recommendations from their ACHD specialty providers?

5. Does receipt of a completed PARF by their ACHD provider improve self-reported level of physical activity?

The study design included an enrollment baseline and post assessment phase as well as the active implementation of the PARF tool utilization at a routine clinic visit. Study participants were recruited on basis of anticipation of a routine ACHD clinic visit to be scheduled within the next 6 months and no special study-only appointments were to be scheduled as well as no virtual visits via fax or email of the PARF form to the providers for completion remotely.

Participants completed the Stanford Brief Activity Survey (SBAS) [11] Fig. 1, and the Stanford Patient Education Research Questionnaire for Chronic Disease (SPERC) [11] for baseline data in the initial enrollment phase. The SBAS focused on leisure and work physical activity, categorized into five levels of frequency and degrees of effort. The SPERC focused on confidence in managing symptoms during various activities of daily living as well as physical exercise.

The SBAS questionnaire classified leisure time physical activity into five categories (see Fig. 1):

1. Most of my time sitting

2. Light exercise on weekends

3. Three times/week moderate activity $15-45 \mathrm{~min}$

4. Regular moderate/vigorous exercise 3 times/week for $30 \mathrm{~min}$ or more

5. Moderate/vigorous exercise $30 \mathrm{~min} 5$ days/week

Participants received a Physical Activity Recommendation Form (PARF) Fig. 2, with written instructions for utilization of the form at their next routine ACHD Provider clinic visit. The PARF was the key tool, designed from a template shared by Dr. Graham Stuart (UK) [9] for this study, to empower ACHD patients to discuss physical activity recommendations with their ACHD specialty provider. The PARF form was modified from the UK adolescent focused template with minor change for adult focus following guidelines from American Heart Association and US Department of Health and Human Services for the US implementation. The PARF form was to be completed by the ACHD provider (MD, ARNP, PA) during visit with the copy given back to patient as a written reminder to enhance activity confidence with some recommendations. Following use of the PARF, study participants completed a second SBAS and a PARF Utilization Satisfaction Survey, both returned in a pre-addressed/postage paid envelope via regular mail to the investigators. Patients could mail the form from their home mailbox in the without need to walk or travel to a post office and thus very convenient and not a deterrent to the planned return of the two forms via regular mail. Electronic return of forms was considered but not utilized due to constraints with IRB approval.

\section{Results}

The study results effectively addressed all of the research questions and confirmed suspicion of a sedentary lifestyle of a large portion of ACHD patient sample, representative of the larger population. The baseline activity surveys provided activity data as well as lifestyle and quality of life as related to daily activity level (Table 3 ). The study sample was representative of the ACHD population and ACHA membership, which is reflected in the ACHA membership data: female 12,640 and male 5911, undeclared 2474. Thus, an expected increased number of female study participants, but noted a higher educational level than expected. Conference attendance alone and a desire to connect with other CHD peers is expected, but one might argue that higher educational level may be the impetus for this desire for ACHA membership and participation in such conferences and thus pose a demographic study bias.

Data analysis grouped activity levels as follows: (1) not active (2) insufficiently active (3) sufficiently active. Analysis of questionnaire data also categorized the 1-10 scored symptom management confidence into three groups: (1-4) low confidence (5-7) moderately confident (8-10) highly confident. Four additional questions were specifically analyzed to determine impact of symptoms and interference with activities of daily living and exercise. The analysis of the data was limited due to poor return rate of complete packets with the post study SBAS and satisfaction survey. Sixty eight of the eighty-two patients recruited completed enrollment and completion of all of the baseline data 


\section{Stanford Brief Activity Survey}

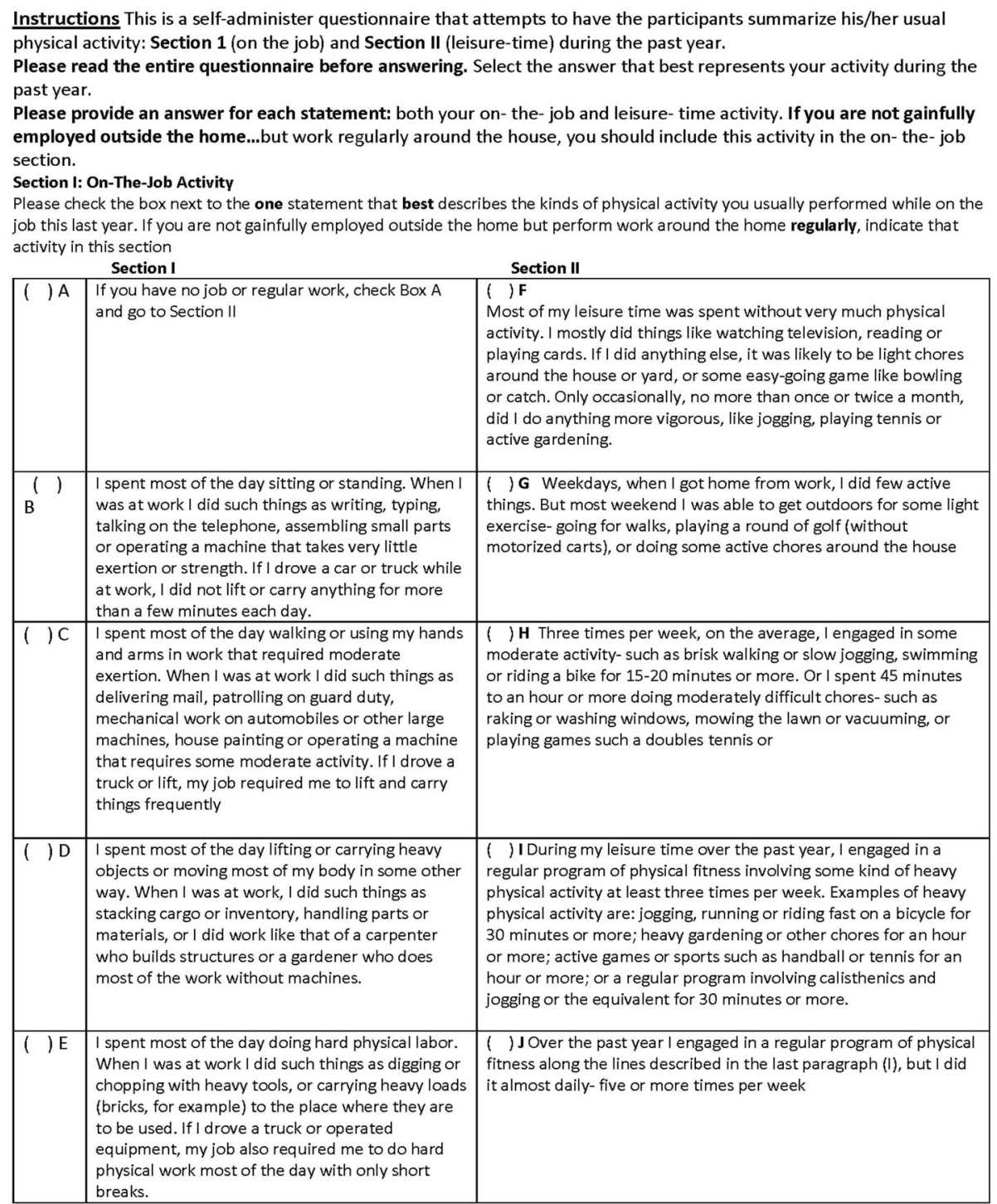

Fig. 1 Stanford Brief Activity Survey. This survey was used to get base line leisure and occupational activity level of study participants

surveys. However, 12 patients returned the entire packet for analysis via mail of all post study components and 8 others sent back partial forms. Many other participants called or emailed with apology that they had lost their packet of forms or didn't think to take the PARF with them when they went for ACHD appointment.

Summarization of the key results from the data analyzed and depicted on these graphics, primarily confirmed suspicion of overall inactive or sedentary lifestyle. Baseline data analysis determined $33 \%$ of the study participants were not active, $43 \%$ were insufficiently active, and $24 \%$ were sufficiently active to obtain activity related health benefits. The majority of the SPERC scores for all four indicators were in the 8-10 range, indicative of participant confidence in managing symptoms impacting activity of daily living. Lifestyle impact related to managing symptoms of fatigue, pain, and emotional distress, however, were reported with much less confidence in the $3-5$ range. $80 \%$ of the respondents on the PARF Utilization Survey reported that use gave them more confidence in increasing activity level and less anxiety about exercise. 90\% recommended PARF use for other ACHD patients. $50 \%$ reported an increase in physical activity following use of the PARF and study participation. The survey provided only a choice of yes or no with a space for comments in response to the questions, thus is there is no information as to why only $50 \%$ increased their activity level, or how much they increased. One 


\begin{tabular}{|c|c|c|c|c|}
\hline \multicolumn{3}{|c|}{ "Study Form: unauthorized duplication or general clinical use is prohibited by the investigators } & & \multirow{2}{*}{$\begin{array}{l}\text { (PARF-US) Adapted } \\
\text { with -ermission } \\
\text { from: Heart } \\
\text { research.uk (2014) }\end{array}$} \\
\hline \multicolumn{4}{|c|}{ ACHD Physical Activity Recommendations Form } & \\
\hline \multicolumn{2}{|c|}{ 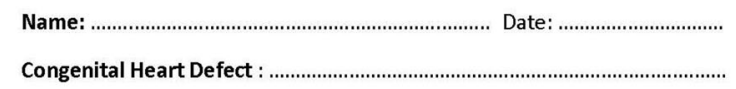 } & \multicolumn{3}{|c|}{$\begin{array}{l}\text { Study PI Contact: Teresa Lyle DNP, ARNP, CPNP } \\
\text { Mobile\#: (770) 289-7189 } \\
\text { Email: tlyle@flsouthern.edu }\end{array}$} \\
\hline \multicolumn{3}{|c|}{ Intensity of activity/exercise recommended } & \multicolumn{2}{|c|}{ Check Appropriate Box(s) } \\
\hline Low intensity & \multicolumn{2}{|c|}{$\begin{array}{l}\text { Active, moving about, but no increase in HR } \\
\text { or breathing i.e. home chores, walk/strolling, Tai Chi }\end{array}$} & & \\
\hline Moderate intensity & \multicolumn{2}{|c|}{$\begin{array}{l}\text { Breathing harder but can still talk or sing i.e. Pilates, } \\
\text { Yoga, light jogging, leisure biking, swimming, dancing }\end{array}$} & & \\
\hline Vigorous intensity & \multicolumn{2}{|c|}{$\begin{array}{l}\text { Heart beats much faster - difficult to talk i.e. running, } \\
\text { bike: spinning/mountain, Zumba, kickboxing }\end{array}$} & & \\
\hline \multicolumn{3}{|c|}{ Amount of activity/exercise recommended } & \multicolumn{2}{|c|}{ Check Appropriate Box } \\
\hline $\begin{array}{l}\text { At least } 30 \text { mins per } \underline{d a \gamma} \ldots \\
\text { OR ... } 150 \text { min per week }\end{array}$ & \multicolumn{2}{|l|}{$\begin{array}{l}\text { American College of Sports Medicine- } \\
\text { Physical Activity Guidelines (2008) }\end{array}$} & & \\
\hline $10-30$ minutes/day & \multicolumn{2}{|c|}{$\begin{array}{l}\text { "Any activity is better than no activity" Health \& Human Services } \\
\text { Physical Activity Guidelines (2008) }\end{array}$} & & \\
\hline Other: & \multicolumn{2}{|l|}{ Please specify: } & & \\
\hline \multicolumn{2}{|c|}{\begin{tabular}{|l|} 
Types of activity/exercise to recommend \\
\end{tabular}} & \multicolumn{3}{|c|}{ Circle as appropriate } \\
\hline \multirow{2}{*}{\multicolumn{2}{|c|}{ Aerobic- (walking, swimming, running, jumping rope, racquet sports, etc.) }} & \multirow{2}{*}{\multicolumn{3}{|c|}{ Comment: }} \\
\hline & & & & \\
\hline \multirow{2}{*}{\multicolumn{2}{|c|}{$\begin{array}{l}\text { Resistance- (Weight lifting with dumbbells/machine, stretch-bands, } \\
\text { pull / push up body weight, etc.) }\end{array}$}} & OK & AVOID & OTHER \\
\hline & & Comment: & & \\
\hline \multicolumn{2}{|c|}{ Types of activity/exercise to avoid } & \multicolumn{3}{|c|}{ Circle as appropriate } \\
\hline \multirow{2}{*}{\multicolumn{2}{|c|}{ Activities with a high risk of impact (football, hockey, boxing, Martial arts) }} & OK & AVOID & OTHER \\
\hline & & Comment: & & \\
\hline \multirow{2}{*}{\multicolumn{2}{|c|}{ Activities with a high risk of cuts, scrapes and bruises (rock climbing, etc.) }} & OK & AVOID & OTHER \\
\hline & & Comment: & & \\
\hline \multicolumn{2}{|l|}{ Competitive sport } & \multicolumn{3}{|c|}{ Check appropriate box } \\
\hline \multicolumn{2}{|c|}{$\begin{array}{l}\text { Avoid all competitive sports (team sports leagues, masters swimming } \\
\text { competitions, marathons, triathlons, bike races, etc.) }\end{array}$} & \multicolumn{3}{|c|}{ Comment: } \\
\hline \multicolumn{2}{|c|}{ May participate, but rest when necessary. } & \multicolumn{3}{|l|}{ Comment: } \\
\hline \multicolumn{2}{|c|}{ May participate fully in all competitive sports. } & \multicolumn{3}{|l|}{ Comment: } \\
\hline \multicolumn{5}{|c|}{ Exercise capacity considerations for vigorous activity/exercise/sports } \\
\hline $\begin{array}{l}\text { Peak Heart Rate }(\mathrm{bpm}) \\
\text { Other: }\end{array}$ & Six-minute walk test $(\mathrm{m})$ & - VO2peak $(\mathrm{ml} / \mathrm{kg}$ & (min) & \\
\hline Additional Comments/Re & mendations: & & & \\
\hline
\end{tabular}

Authorized by:

Valid until / Review date: (Rev.8.5.14)

Fig. 2 Physical Activity Recommendation Form. This form was adapted from Dr. Graham Stuart's recommendation form and was given to study participants for their adult congenital cardiologist to complete at the participant's next clinic visit

person did comment that he/she was already meeting the recommended level of activity.

\section{Discussion}

Limitations in post PARF study data analysis was encountered due to several factors related to logistics with return mail and loss of the actual PARF following enrollment. An unanticipated ACHA office move \& address change contributed to possible loss of returned surveys via mail. The variable time frame from enrollment in study to ACHD provider visit in several cases was the suspected cause of loss of the PARF.

Although detailed but very simply step by step written instructions accompanied the PARF, several participants reported being confused about what to do with the PARF. Therefore, an additional limitation in the open-ended closure of study for follow through with the PARF \&/or return of post surveys may have been impacted by participant's possible memory/executive function. Several patients that failed to return the full packet via mail called or emailed the investigator with apology and admission of losing the 
Table 3 Baseline activity data summarized from the enrollment questionnaires. This table summarizes the baseline activity data from the Stanford brief activity survey and the Stanford Patient Education Research Questionnaire for Chronic Disease

\begin{tabular}{|c|c|}
\hline \multicolumn{2}{|c|}{ Baseline Activity Data } \\
\hline $33 \%$ & Not Active \\
\hline $43 \%$ & Insufficiently Active \\
\hline $24 \%$ & Sufficiently Active to attain health benefits \\
\hline \multicolumn{2}{|c|}{ Lifestyle Indicators } \\
\hline $80 \%$ & $\begin{array}{l}\text { Reported use of PARF gave more } \\
\text { confidence and less anxiety about being } \\
\text { active / exercise }\end{array}$ \\
\hline $90 \%$ & $\begin{array}{l}\text { Recommended PARF for others to use with } \\
\text { ACHD visit/ discussion with providers }\end{array}$ \\
\hline $50 \%$ & $\begin{array}{l}\text { Stated they increased their level of physical } \\
\text { activity after use of the PARF }\end{array}$ \\
\hline $42 \%$ & Expressed confidence in managing anxiety \\
\hline
\end{tabular}

forms and / or failing to remember to take them to their appointment. Some had routine appointments planned or scheduled within 3-6 months following enrollment, which was an inclusion criterion for participation. This omission of follow through was not perceived as a failure to engage, but an issue of the variable time interval and possibly result of being without interim reminder communication. Neuro-cognitive issues have been known to occur in the ACHD population especially with regard to executive function $[12,13]$.

In addition, this convenience sample was representative of conference attendee and of members of the ACAH, a majority female. The ACHA currently does not collect data on ethnicity, race, marital status or education, therefore no conclusions can be drawn about the representation of the sample size.

\section{Conclusion}

The Physical Activity Recommendation Form Feasibility Study raised awareness and increased confidence in discussing physical activity with providers for ACHA patient participants. Feasibility of use of the PARF was confirmed and felt to be beneficial by patients and providers. Baseline data analysis from the Stanford Activity Surveys revealed that ACHD survivors were not sufficiently active to attain health benefits, even with household and leisure activity included and activity not just defined as physical exercise. Additional research to improve confidence and increased physical activity in ACHD patients is needed. Further study would afford opportunity to evaluate not only increased motivation but the impact of PARF utilization on the actual increase in activity level with a tool to measure compliance. Possible next steps would be to have a PARF available on the ACHA website as a tool that could be downloaded by members and ACHD providers for utilization during routine specialty follow up visits. ACHD provider recommendations to facilitate healthy physical activity vs. formalized exercise prescriptions that may require special diagnostic testing, to be considered for inclusion in next revision of the ACHD Management Guidelines [14]. Feasibility of PARF use and subsequent benefit to the ACHD patient population was demonstrated in this study. Empowerment of both the patients and providers with the ease of access/availability of a tool such as the PARF is needed to facilitate improvement in future physical activity and overall health outcomes.

\section{Abbreviations \\ ACHA: Adult Congenital Heart Association; ACHD: Adults with Congenital Heart Disease; DHHS: Department of Health and Human Services; MI: Myocardial Infarction; PARF: Physical Activity Recommendation Form; SBAS: Stanford Brief Activity Survey; SPERC: Stanford Patient Education Research Questionnaire for Chronic Disease; UK: United Kingdom}

\section{Acknowledgements}

Special acknowledgement for Dr. Graham Stuart for inspiring the project and providing the initial template from his work in the UK that facilitated the revision of the Physical Activity Recommendation Form (PARF) used for this study. Emily Rose, BS (Florida Southern College Health Sciences student): data analysis and Sara Moss (University of North Florida Exercise Science Student): data analysis.

\section{Funding}

There were no financial or non-financial competing interests involved. There was no grant or private funding. There was no compensation for study participants.

Availability of data and materials

Data sharing is not applicable to this article as no datasets were generated or analyzed during the current study.

\section{Authors' contributions}

Study design/implementation (50/50) IRB/Manuscript writing (80/20 Lyle/ Hartman). All authors read and approved the final manuscript.

Ethics approval and consent to participate

The study received Institutional Review Board Approval from Florida Southern College, The University of North Florida, and the Research Committee at the Adult Congenital Heart Association. Informed consent was obtained from all participants and anonymity maintained with deidentification of all surveys in the study binder.

\section{Consent for publication}

Our manuscript contains no individual personal data.

\section{Competing interests}

The authors declare they have no competing interests.

\section{Publisher's Note}

Springer Nature remains neutral with regard to jurisdictional claims in published maps and institutional affiliations.

\section{Author details}

${ }^{1}$ Caylor School of Nursing, Lincoln Memorial University, 3102 E. 138th Ave, Tampa, FL 33613, USA. '2Department of Clinical and Applied Movement Sciences, University of North Florida, Jacksonville, Florida, USA. 
Received: 21 June 2018 Accepted: 27 September 2018

Published online: 25 October 2018

\section{References}

1. Chaix M, et al. Review: Risks and benefits of exercise training in adults with congenital heart disease. Candian Journal of Cardiology. 2016;(4):459-66.

2. Dua J, et al. Physical activity levels in adults with congenital heart disease. European Journal of Cardiovascular Prevention and Rehabilitation. 2007;14:287-93.

3. Sandberg C, Pomeroy J, et al. Habitual physical activity in adults with congenital heart disease compared with age and sex matched controls. Can J Cardiol. 2016;36:547-55.

4. Rodriguez FH III, Marelli AJ. The epidemiology of heart failure in adults with congenital heart disease. Heart Fail Clin. 2014;10:1-7 Retrieved from: https:// doi.org/10.1016/j.hfc.2013.09.008.

5. American College of Sports Medicine (2008) Physical activity guidelines. Retrieved from www. acsm.org/activityguidelines.

6. US department of Health and Human Services 2008 Physical activity guidelines for American retrieved from https://health.gov/paguidelines/ guidelines/. Updated 10/4/2017.

7. Lui G, Ferandes S, McElhinney D. Management of cardiovascular risk factors in adults with congenital heart disease. Journal of American Heart Association. 2014;3. https://doi.org/10.1161/JAHA.114.001076.

8. Swan L, Hillis W. Exercise prescription in adults with congenital heart disease: a long way to go. Heart. 2000;83:685-7.

9. Stuart G, Horn R. Physical activity recommendation form. Research form shared with permission for modification and use from heart research. Uk (nhs), Bristol, United Kingdom. 2014.

10. Adult Congenital Heart Association (ACHA). https://www.achaheart.org

11. Stanford Patient Education Research Center, Self-management Activity Questionnaire, (Stanford University School of Medicine with permission to use and modify questionnaire) Retrieved from http://patienteducation.stanford.edu

12. Klouda $L$, et al. Neurocognitive and executive functioning in adult survivors of congenital heart disease. Congenit Heart Dis. 2017;12(1):91-8.

13. Calderon J, Bellinger $D$. Executive function deficits in congenital heart disease: why is intervention important? Cardiol Young. 2015;25(7):1238-46.

14. Warnes CA, Williams RG, Bashore TM, Child JS, et al. Guidelines for the management of adults with congenital heart disease. Circulation. 2008:2395-451.

Ready to submit your research? Choose BMC and benefit from:

- fast, convenient online submission

- thorough peer review by experienced researchers in your field

- rapid publication on acceptance

- support for research data, including large and complex data types

- gold Open Access which fosters wider collaboration and increased citations

- maximum visibility for your research: over $100 \mathrm{M}$ website views per year

At $\mathrm{BMC}$, research is always in progress.

Learn more biomedcentral.com/submissions 